\title{
IDENTIFIKASI BENCANA ROB DAN PENGARUHNYA PADA KERENTANAN SOSIAL DI KECAMATAN SEMARANG UTARA, KOTA SEMARANG
}

\section{IDENTIFICATION OF THE COASTAL INNUDATION DISASTER AND ITS EFFECT ON SOCIAL VULNERABILITY IN NORTH SEMARANG DISTRICT, SEMARANG CITY}

\author{
Vica Gitya Haryanti ${ }^{a}$, Nany Yuliastuti ${ }^{b}$ \\ aDepartemen Perencanaan Wilayah dan Kota; Universitas Diponegoro, Semarang; vica.gitya19@pwk.undip.ac.id \\ bDepartemen Perencanaan Wilayah dan Kota; Universitas Diponegoro, Semarang; n.yuliastuti@pwk.undip.ac.id
}

Info Artikel:

- Artikel Masuk: 2 Maret 2021

\begin{abstract}
ABSTRAK
Rob yang masih terjadi hingga saat ini di kawasan pesisir Kota Semarang menyebabkan kawasan terdampak menjadi rentan secara sosial. Penelitian ini bertujuan untuk mengidentifikasi pengaruh bencana rob pada kondisi kerentanan sosial di Kecamatan Semarang Utara, Kota Semarang. Penelitian ini dilakukan pada 9 kelurahan di Kecamatan Semarang Utara dengan sampel 99 KK dengan mengambil data-data yang terkait dengan gender, sex ratio, kepadatan penduduk, pendidikan, pendapatan dan masyarakat berkebutuhan khusus. Metode yang digunakan dalam penelitian ini adalah metode kuantitatif dengan menggunakan teknik analisis deskriptif kuantitaif dan analisis skoring. Analisis dilakukan dengan menggunakan analisis deskriptif terhadap kondisi rob yang menyebabkan kerentanan sosial dan analisis skoring yang menghasilkan kondisi kerentanan sosial kerentanan sosial di Kecamatan Semarang Utara. Hasil dari penelitian ini adalah bencana rob di Kecamatan Semarang Utara mempengaruhi kerentanan sosial yang diklasifikasikan memiliki 3 kategori yaitu kerentanan sosial tinggi, sedang dan rendah. Kerentanan sosial yang tinggi mendominasi nilai kerentanan sosial di Kecamatan Semarang Utara karena 4 dari 9 kelurahan di Kecamatan Semarang Utara memiliki nilai kerentanan yang tinggi akibat bencana rob.
\end{abstract}

Kata Kunci : Kerentanan Sosial, Permukiman, Rob

\begin{abstract}
Coastal innudation which is still happening today in the coastal area of Semarang City has caused the affected area to become socially vulnerable. This study aims to identify the effect of coastal innudation on conditions of social vulnerability in North Semarang District, Semarang City. This research was conducted in 9 sub-districts in North Semarang District with a sample of 99 households by taking data related to gender, sex ratio, population density, education, income and people with special needs. The method used in this study is a quantitative method using quantitative descriptive analysis techniques and scoring analysis. The analysis was carried out using descriptive analysis of the condition of coastal innudation which caused social vulnerability and scoring analysis which resulted in the level of social vulnerability in the District of North Semarang. The result of this research is that the coastal innudation in North Semarang District affects social vulnerability which is classified into 3 categories, namely high, medium and low social vulnerability. High social vulnerability dominates the social vulnerability value in North Semarang Sub-District because 4 out of 9 urban villages in North Semarang Sub-District have a high vulnerability value due to coastal innudation.
\end{abstract}

Keyword: Social Vulnerability, Housing, Coastal Innudation 


\section{PENDAHULUAN}

Bencana merupakan suatu peristiwa yang terjadi secara tiba-tiba yang menyebabkan gangguan atau kerusakan serius terhadap fungsi suatu komunitas atau masyarakat. Hal ini berupa kerugian material, ekonomi, fisik/lingkungan hingga jiwa dengan skala cakupan dan beban yang melebihi kemampuan komunitas atau masyarakat terdampak untuk mengatasi kondisi tersebut dengan menggunakan sumber daya pribadinya (UNISDR, 2004). Bencana yang terjadi di seluruh bagian Indonesia sangat bervariasi.

Dari seluruh bencana yang terjadi tahun 2018, BNPB mencatat, bencana hidrometeorologi paling dominan. Jumlah kejadian puting beliung 605 kejadian, banjir 506, kebakaran hutan dan lahan 353, longsor 319, erupsi gunungapi 55, gelombang pasang dan abrasi 33, gempa bumi yang merusak 17, dan tsunami 1 kali (BNPB, 2018). Banjir menempati posisi kedua, dimana banjir yang terjadi diakibatkan ulah manusia yang menyebabkan saluran air terhambat hingga penurunan muka tanah yang disebabkan pemanfaatan air tanah secara besar-besaran dan faktor-faktor alam seperti naiknya permukaan air laut

Peningkatan frekuensi dan intensitas banjir yang disebabkan oleh kenaikan permukaan air laut secara global dikenal sebagai banjir air pasang. Menurut Suhelmi (2009), fenomena banjir yang disebabkan oleh kenaikan muka air laut disebut banjir rob, dimana daerah pesisir memiliki resiko lebih besar terhadap rob. Kota Semarang merupakan salah satu kota yang memiliki variasi kerawanan banjir rob mulai dari rendah hingga tinggi. Hal ini menyebabkan kualitas lingkungan dan kehidupan masyarakat secara drastis menurun, didukung pula dengan cakupan luasan rob yang semakin membesar dikarenakan terjadinya penurunan muka tanah di waktu yang sama mencapai angka 9-13 cm/tahun (Yuwono, 2013).

Rob berbeda dengan bencana seperti gempa ataupun tsunami. Meskipun bencana ringan relatif tidak berbahaya secara langsung, namun pada puncaknya atau apabila terjadi secara terus menerus maka akan menimbulkan trauma baik pada fisik dan emosional, korban jiwa, kerugian materi hingga sampai pada titik menghancurkan suatu komunitas di dalam masyarakat (Flanagan et al., 2011).

Alwang et al., (2001) menjelaskan bahwa suatu kawasan rawan bencana yang tidak memiliki sistem manajemen guna menanggulangi dan melakukan mitigasi bencana akan menyebabkan kerentanan pada masyarakat dan berdampak salah satunya pada struktur sosial dari masyarakat yang bermukim pada daerah tersebut. Adger (2006) mendefinisikan kerentanan sebagai paparan kelompok atau stres individu karena perubahan sosial dan lingkungan yang mengganggu penghidupan. la juga mendefinisikan Kerentanan Sosial sebagai paparan stres individu atau kelompok dari risiko eksogen, terutama dari guncangan iklim. Meningkatnya kerentanan masyarakat terhadap risiko bencana rob juga disebabkan oleh standar perumahan dan bahan bangunan yang buruk, serta lokasi wilayah yang dekat sungai atau laut juga dapat meningkatkan kerentanan penduduk (Yuliastuti et al., 2016).

Secara teknis menurut Buchori et al., (2018) dan Marfai \& King (2007), innudation yang diperparah dengan meningkatnya permukaan air laut sehingga menyebabkan banjir pada daerah pesisir (coastal flooding) disebut sebagai hydro-meteorological hazard yang dalam istilah lokal dikenal sebagai rob. Sementara itu, apabila diamati secara khusus, rob yang terjadi secara permanen disebut dengan genangan (innudation) dan rob yang terjadi pada waktu-waktu tertentu seperti saat air laut pasang disebut dengan banjir (coastal flooding).

Marfai \& King (2007) menyatakan bahwa rob merupakan ancaman utama pada daerah pesisir yang mampu menyebabkan hilangnya nyawa atau kerugian materi lainnya. Kecamatan Semarang Utara memiliki ancaman berupa bencana rob yang cukup bervariasi, daerah dengan ancaman rendah berada pada Kelurahan Bulu Lor, lalu untuk kawasan dengan ancaman rob sedang berada pada Kelurahan Bandarharjo, Panggung Lor dan Plombokan, sedangkan kawasan dengan ancaman rob tinggi berada pada Kelurahan Dadapsari, Kuningan, Panggung Kidul, Purwosari dan Tanjung Mas. Lokasi - lokasi yang termasuk pada zonasi rawan rob dengan tingkat kerawanan yang tinggi juga merupakan kawasan yang ditetapkan sebagai kawasan dengan permukiman kumuh berdasarkan SK Walikota Semarang No. 050/801/2014.

Ancaman yang muncul karena terjadinya rob secara terus menerus dan kumuhnya Kawasan permukiman pada daerah-daerah tersebut, berpotensi membuat nilai kerentanan sosial masyarakat cukup 
Haryanti, Yuliastuti/ Jurnal Pembangunan Wilayah dan Kota, Vol. 17, No. 3, 2021, 287-294

Doi: $10.14710 /$ pwk.v17i3.37022

tinggi. Oleh karena itu, penelitian ini bertujuan untuk mengidentifikasi pengaruh bencana rob pada kondisi kerentanan sosial di Kecamatan Semarang Utara.

\section{DATA DAN METODE}

Penelitian dilakukan pada Kecamatan Semarang Utara, Kota Semarang. Kecamatan Semarang Utara memiliki 9 kelurahan didalamnya, yaitu Kelurahan Kuningan, Dadapsari, Bulu Lor, Plombokan, Panggung Kidul, Panggung Lor, Bandar Harjo, Purwosari dan Tanjung Mas (Gambar 1). Kawasan penelitian pada studi ini memiliki luas sebesar 3,24 $\mathrm{Km}^{2}$.

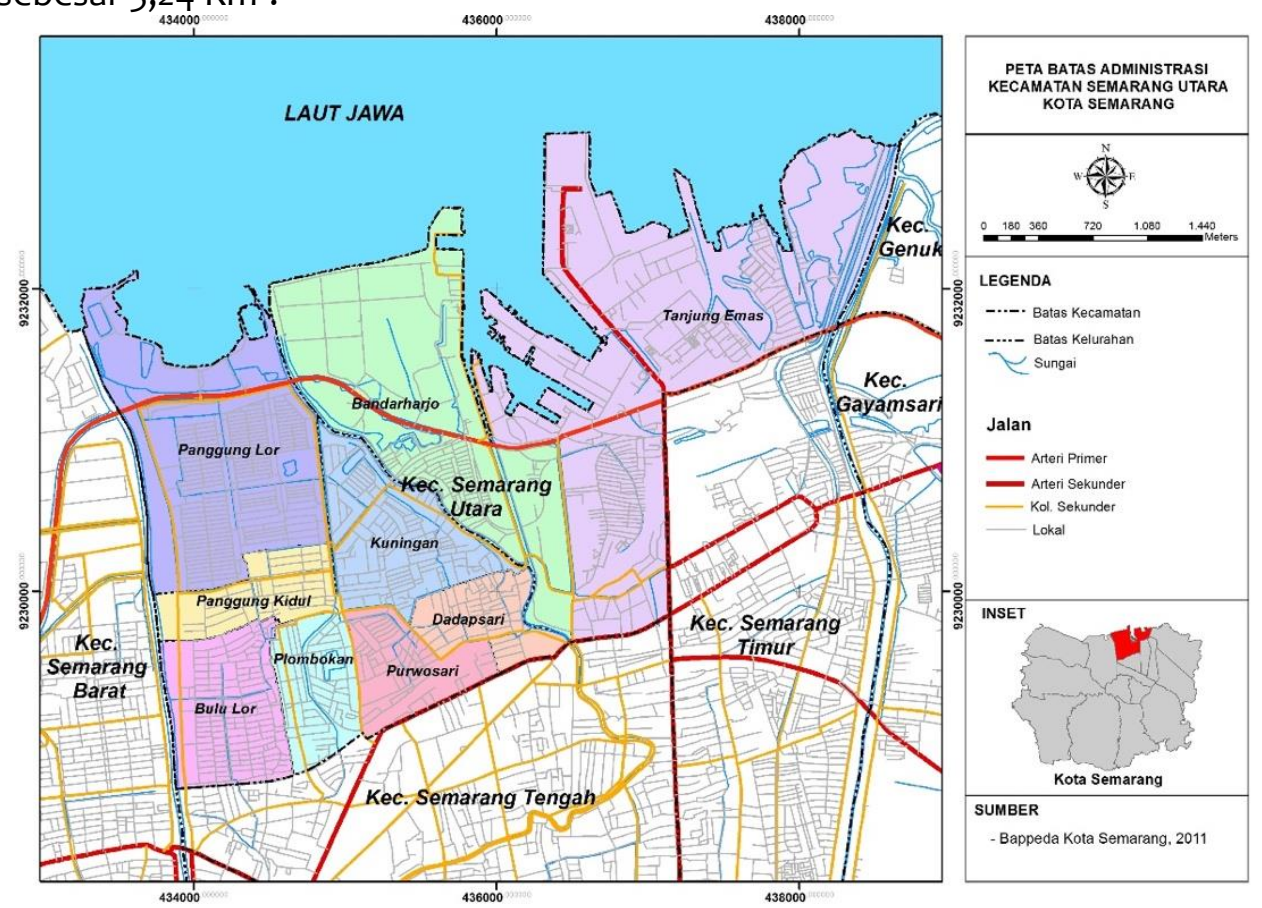

Sumber: Bappeda Provinsi Jawa Tengah Tahun 2011

Gambar 1. Peta Batas Administrasi Wilayah Studi

Data yang akan diolah dalam penelitian ini terbagi dalam beberapa sub variabel. Berdasarkan sintesis dari beberapa literatur mengenai sub variabel penyusun variabel kerentanan sosial, dipilih 6 sub variabel yang akan digunakan guna mengukur tingkat kerentanan sosial. Sub variabel ini terdiri dari gender, usia, kepadatan penduduk, pendidikan pekerjaan/pendapatan dan penyandang berkebutuhan khusus.

Metode penelitian yang digunakan dalam penelitian ini adalah penelitian kuantitatif deskriptif. Menurut Wallace dalam Susanti (2013) penelitian kuantitatif adalah penelitan yang melibatkan lima komponen informasi ilmiah, yaitu teori, hipotesis, observasi, generalisasi empiris, dan penerimaan atau penolakan hipotesis. Selain itu, mengandalkan adanya populasi dan teknik penarikan sampel, menggunakan kuesioner untuk pengumpulan datanya, mengemukakan variabel-variabel penelitian dalam analisis datanya, dan berupaya menghasilkan kesimpulan secara umum, baik yang berlau untuk populasi dan/ atau sampel yang diteliti.

Penelitian kuantitatif dipilih sebagai metode dikarenakan dalam menentukan nilai kerentanan sosial memerlukan variabel-variabel yang dijadikan dasar penentuan nilai kerentanan sosial, dimana variabel tersebut didapatkan dengan melakukan sintesa variabel terhadap kajian literatur dan teori-teori yang telah dikembukakan para ahli, sehingga menghasilkan variabel-variabel seperti kerentanan sosial yang terdiri dari gender, pendidikan, usia, kepadatan penduduk, warga berkebutuhan khusus serta pekerjaan dan pendapatan (Birkmann, 2007; Cutter et al., 2000; Cutter \& Finch, 2008; Emrich \& Cutter, 2011; Flanagan et al., 2011). 
Teknik sampling yang digunakan yaitu proportional random sampling. Teknik ini merupakan cara mengambil sampel, dimana setiap individu atau unit dalam keseluruhan populasi memiliki kesempatan yang sama untuk dipilih, namun dilakukan pembagian sampel secara proporsional (Tika, 2005).

Teknik analisis yang digunakan adalah analisis deskriptif kuantitatif dan analisis skoring. Analisis skoring diilakukan dengan pemberian skor pada setiap variabel yang digunakan dalam penelitian. Hasil dari scoring setiap variabel menunjukkan nilai kerentanan sosial pada masing-masing sub variabel. Melalui hasil scoring masing-masing sub variabel kemudian dilakukan penjumlahan skor setiap sub variabel dan didapatkan hasil akhir berupa nilai kerentanan sosial Semarang Utara terhadap bencana rob. Berikut adalah kelas skor yang digunakan dalam penelitian ini yang dapat dilihat pada Tabel 1.

Tabel 1. Kriteria Nilai Sub Variabel

\begin{tabular}{llll}
\hline Sub Variabel & Nilai & Kriteria & Keterangan \\
\hline Gender & 1 & $4-6,6$ & Berdasarkan Hasil Perhitungan \\
& 2 & $6,7-9,3$ & Kelas Interval Kuisioner Sub \\
& 3 & $9,4-12$ & Variabel Gender \\
\hline Pendidikan & 1 & $2-3,3$ & Berdasarkan Hasil Perhitungan \\
& 2 & $3,4-4,7$ & Kelas Interval Kuisioner Sub \\
& 3 & $4,6-6$ & Variabel Pendidikan \\
\hline Pekerjaan/ & 1 & $3-5,0$ & Berdasarkan Hasil Perhitungan \\
Pendapatan & 2 & $5,1-7$ & Kelas Interval Kuisioner Sub \\
& 3 & $7,1-9$ & Variabel pekerjaan/pendapatan \\
\hline Kebutuhan & 3 & $44-59$ Jiwa/Kelurahan & Berdasarkan Data BPS Kota \\
Khusus & 2 & $27-43$ Jiwa/Kelurahan & Semarang, 2018 \\
& 1 & $10-26$ Jiwa/Kelurahan & \\
\hline Usia & 3 & $38,83-39,01$ & Berdasarkan Rasio Ketergantungan \\
& 2 & $38,64-38,82$ & Penduduk Usia Tua Dan Balita \\
& 1 & $38,45-38,63$ & Terhadap Penduduk Berusia \\
\hline Kepadatan & 3 & $201-400$ & Produktif \\
Penduduk & 2 & $150-200$ & Berdasarkan Perhitungan Jumlah \\
& 1 & $<150$ & Penduduk Dibagi Luas Wil \\
\hline Sumber: Hasil Analis & &
\end{tabular}

Sumber: Hasil Analisis, 2019

Dalam analisis skoring, Evans et al (2014) menggunakan perhitungan z-score guna mengetahui nilai kerentanan sosial dengan kriteria sebagai berikut (Tabel 2):

Tabel 2. Klasifikasi Sovi Menurut Z-Score

\begin{tabular}{cc}
\hline Nilai ZscoreS & Interpretasi SoVI \\
\hline$<(-0.5)$ & Limited social vulnerability \\
& (kerentanan sosial rendah/terbatas) \\
$(-0,5)-(0,5)$ & Moderate social vulnerability \\
& (kerentanan sosial sedang) \\
$>(0,5)$ & Elevated social vulnerability \\
& (Kerentanan sosial tinggi)
\end{tabular}

Sumber: Evans et al, 2014

Berdasarkan Tabel 1. mengenai kriteria yang akan digunakan dalam pemberian skor pada setiap sub variabel, selanjutnya seluruh skor dari masing-masing sub variabel tersebut di jumlahkan lalu dilakukan perbandingan z-score. Zscore dalam analisis kerentanan sosial menurut Gu (2018) digunakan untuk membandingkan sekelompok data dari variabel dalam kondisi distribusi normal. 


\section{HASIL DAN PEMBAHASAN}

Nilai kerentanan sosial di Kecamatan Semarang Utara yang telah diamati melalui 6 sub variabel berdasarkan sintesa literatur yang telah dipaparkan sebelumnya, dimana 6 sub variabel ini terdiri dari gender, usia, pendidikan, kepadatan penduduk, pekerjaan dan pendapatan serta penduduk dengan kebutuhan khusus atau penyandang disabilitas. Tiap-tiap sub variabel yang telah ditentukan, kemudian di analisis dengan melakukan kategorisasi dan pemberian skor sesuai nilai kerentanan yang telah ditentukan dengan unit analisis kelurahan pada Kecamatan Semarang Utara.

Pemberian skor pada masing-masing variabel penyusun ini guna menganalisis nilai kerentanan sosial pada Kecamatan Semarang Utara. Setelah dilakukannya rekapitulasi skoring seluruh variabel pada masingmasing kelurahan di Kecamatan Semarang Utara. Selanjutnya, dilakukan perhitungan z-score sebagai tahap lanjutan dalam skoring nilai kerentanan sosial. Z-score dalam analisis kerentanan sosial digunakan untuk membandingkan sekelompok data dari variabel dalam kondisi distribusi normal yang selanjutnya akan diinterpretasikan dengan menggunakan kriteria pada Tabel 2, sehingga menghasilkan hasil sebagai berikut (Tabel 3):

Tabel 3. Hasil Skoring dan Interpretasi Kerentanan Sosial

\begin{tabular}{|c|c|c|c|c|c|c|c|c|c|c|}
\hline No & Kelurahan & Usia & Gender & Pendidikan & $\begin{array}{c}\text { Kepadatan } \\
\text { Penduduk }\end{array}$ & $\begin{array}{l}\text { Pekerjaan/ } \\
\text { Pendapatan }\end{array}$ & $\begin{array}{c}\text { Penyandang } \\
\text { disabilitas }\end{array}$ & $\begin{array}{l}\text { Jumlah } \\
\text { skor }\end{array}$ & zscore & $\begin{array}{l}\text { Kerentanan } \\
\text { sosial }\end{array}$ \\
\hline 1 & Bandarharjo & 3 & 3 & 2 & 1 & 3 & 3 & 15 & 1,01 & Tinggi \\
\hline 2 & $\begin{array}{l}\text { Panggung } \\
\text { Lor }\end{array}$ & 2 & 2 & 1 & 1 & 3 & 1 & 10 & $-1,39$ & Rendah \\
\hline 3 & $\begin{array}{l}\text { Tanjung } \\
\text { Emas }\end{array}$ & 2 & 3 & 3 & 1 & 2 & 3 & 14 & 0,53 & Tinggi \\
\hline 4 & Bulu Lor & 2 & 3 & 1 & 3 & 2 & 2 & 13 & 0,05 & Sedang \\
\hline 5 & Plombokan & 2 & 3 & 2 & 2 & 2 & 1 & 12 & $-0,43$ & Sedang \\
\hline 6 & Purwosari & 2 & 2 & 2 & 3 & 2 & 1 & 12 & $-0,43$ & Sedang \\
\hline 7 & Dadapsari & 2 & 3 & 2 & 3 & 3 & 1 & 14 & 0,53 & Tinggi \\
\hline 8 & $\begin{array}{l}\text { Panggung } \\
\text { Kidul }\end{array}$ & 1 & 2 & 2 & 2 & 2 & 1 & 10 & $-1,39$ & Rendah \\
\hline 9 & Kuningan & 2 & 3 & 3 & 3 & 3 & 2 & 16 & 1,49 & Tinggi \\
\hline
\end{tabular}

Sumber: Hasil Analisis, 2019

Setelah diketahui nilai kerentanan sosial pada masing-masing kelurahan dengan menggunakan analisis skoring yang dilanjutkan dengan perhitungan z-score. Dapat diamati bahwa kelurahan-kelurahan dengan nilai kerentanan sosial yang serupa memiliki kondisi sosial yang serupa pula minimal terhadap 1 (satu) sub variabel penyusun. Seperti pada Kelurahan Bandarharjo dengan nilai zscore 1,01; Tanjung Emas dengan nilai zscore 0,53; Kuningan dengan nilai zscore 1,49 dan Dadapsari dengan nilai zscore 0,53 yang memiliki nilai kerentanan sosial tinggi, keempat kelurahan ini memiliki kondisi sosial yang serupa terkait gender dan hampir serupa pada sub-sub variabel lainnya.

Hal yang sama juga dapat diamati pada kelurahan-kelurahan dengan nilai kerentanan sosial sedang yang terdiri dari Kelurahan Bulu Lor dengan nilai zscore 0,05; Plombokan dengan nilai zscore -0,43 dan Purwosari dengan nilai zscore -0,43 dimana ketiga kelurahan ini memiliki kondisi sosial yang serupa terkait kondisi usia dan pekerjaan serta tingkat pendapatan masyarakatnya. Begitu pula dengan kelurahankelurahan dengan nilai kerentanan sosial rendah yang memiliki kondisi sosial yang sama pada kondisi gender dan penduduk dengan kebutuhan khusus. 
Nilai kerentanan sosial pada Kecamatan Semarang Utara dapat diinterpretasikan melalui pemetaan yang dapat dilihat pada Gambar 2, dapat dilihat persebaran berdasarkan nilai kerentanan sosial apabila berdasarkan seluruh analisis sub variabel pada Kecamatan Semarang Utara.

Apabila diamati pada peta nilai kerentanan sosial berdasarkan seluruh sub variabel tersebut, kelurahan-kelurahan yang memiliki nilai kerentanan yang sama mengelompok atau memiliki pola clustered. Hal ini dikarenakan apabila diamati pada peta nilai kerentanan sosial, kelurahan-kelurahan dengan nilai kerentanan tinggi yang ditandai dengan warna merah dan terdiri dari 4 kelurahan yaitu Kelurahan Bandarharjo, Tanjung Emas, Kuningan dan Dadapsari yang mengelompok sepenuhnya dengan kelurahan yang memiliki nilai kerentanan serupa. Kondisi ini berlaku pula pada daerah-daerah dengan nilai kerentanan sedang yang ditandai dengan warna kuning dan daerah dengan nilai kerentanan rendah yang ditandai dengan warna hijau pada peta. Seluruh daerah dengan nilai kerentanan sejenis tidak ada yang menyebar sehingga pola persebaran dapat dikatakan mengelompok atau clustered.

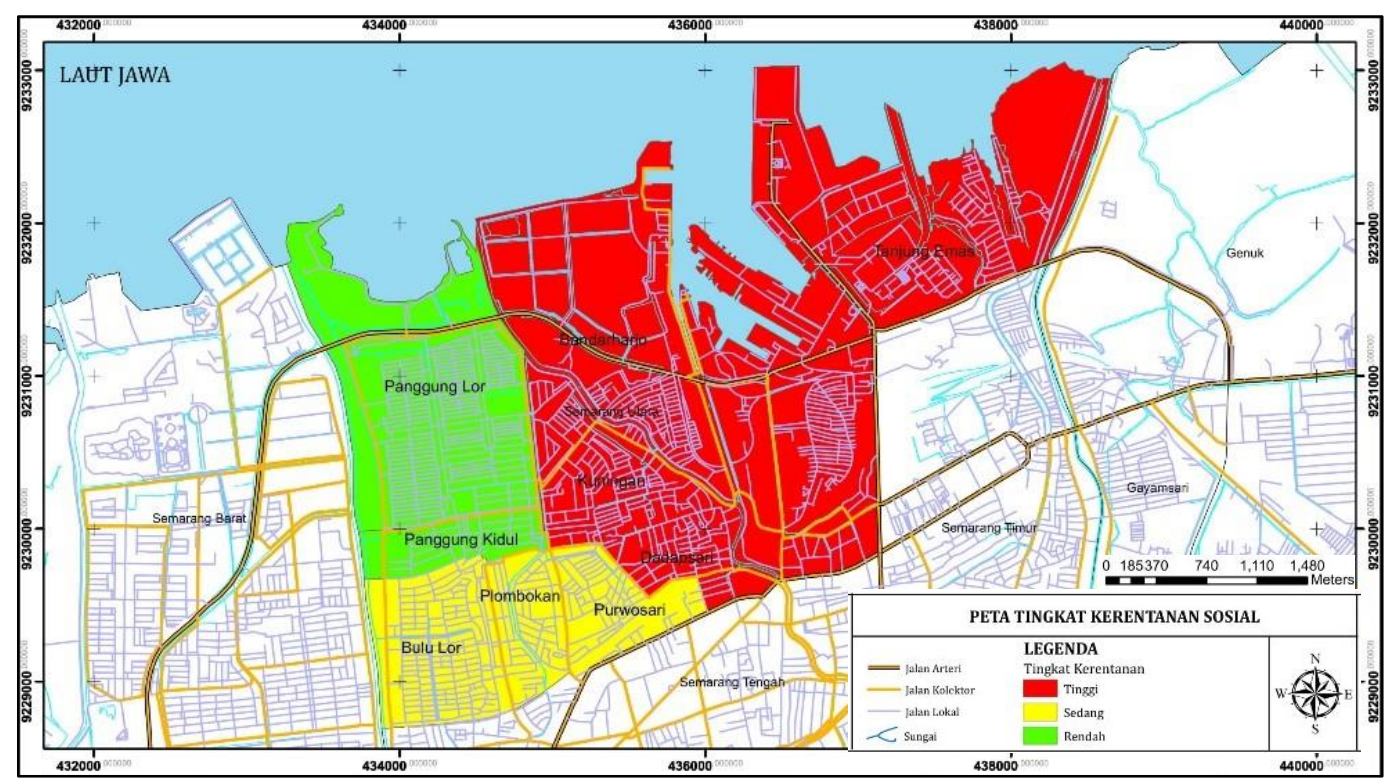

Sumber: Bappeda Provinsi Jawa Tengah Tahun 2015, Analisis Penyusun 2019

Gambar 2. Peta Kerentanan Sosial di Kecamatan Semarang Utara

Nilai kerentanan sosial apabila dinilai melalui sub-sub variabel yang telah ditentukan memiliki 3 kategori yaitu kerentanan tinggi yang terdiri dari Kelurahan Bandarharjo, Tanjung Mas, Kuningan, dan Dadapsari. Kerentanan sedang yang terdiri dari Kelurahan Bulu Lor, Plombokan dan Purwosari. Sementara itu, untuk nilai kerentanan sosial rendah berisikan 2 kelurahan yaitu Panggung Lor dan Panggung Kidul.

Apabila dianalisis lebih lanjut, nilai kerentanan sosial tinggi pada Kelurahan Bandarharjo, Tanjung Mas, Kuningan dan Dadapsari yang memiliki nilai kerentanan sosial yang tinggi, disebabkan oleh sub variabel yang telah dijelaskan sebagaimana sebelumnya. Sub variabel gender dengan rendahnya partisipasi peran wanita saat terjadinya rob serta pasca rob pada seluruh kelurahan terkait sebagaimana dijelaskan Cutter et al (2003) rendahnya partisipasi ini membuat perempuan cenderung memiliki masa yang lebih sulit untuk pulih apabila terpapar bencana atau bahaya lainnya.

Sub variabel lainnya yang mempengaruhi adalah rendahnya tingkat pendidikan serta jenis pekerjaan dan tingkat pendapatan di kelurahan terkait. Hal ini dijelaskan oleh Hizbaron (2015) dimana tingkat pendidikan mempengaruhi pengambilan keputusan untuk pulih saat atau setelah bencana, sedangkan Cutter et al (2003) berpendapat bahwa masyarakat atau individu yang memiliki sumber daya materi yang cukup, mampu pulih dari paparan bencana yang cukup cepat dibandingkan yang tidak memiliki sumber daya materi. Sub variabel pekerjaan dan tingkat pendapatan juga dipengaruhi oleh pendidikan dan usia. 
Sehingga hal ini menunjukan bahwa sub variabel utama yang sangat mempengaruhi Kelurahan Bandarharjo, Tanjung Mas, Kuningan dan Dadapsari memiliki nilai kerentanan sosial yang tinggi adalah sub variabel gender dan sub variabel jenis pekerjaan dan tingkat pendapatan, yang kemudian berkaitan dengan sub-sub variabel lainnya. Hal ini sesuai dengan yang disampaikan oleh Yuwono (2013) yang mengatakan bahwa cakupan luasan bencana rob yang semakin besar dapat menyebabkan kualitas lingkungan dan kehidupan masyarakat secara drastis menurun.

Daerah-daerah dengan nilai kerentanan sosial sedang yang terdiri dari kelurahan Plombokan, Purwosari dan Dadapsari, memiliki kerentanan sosial yang serupa dipengaruhi oleh beberapa sub variabel penyusun nilai kerentanan. Sub-sub variabel tersebut adalah sub variabel gender dan kepadatan penduduk.

Sementara itu, untuk daerah dengan nilai kerentanan sosial rendah yang terdiri dari Kelurahan Panggung Lor dan Panggung Kidul, memiliki kerentanan yang serupa dipengaruhi oleh sub variabel gender dan sub variabel penyandang disabilitas, dimana sub variabel gender memiliki nilai kerentanan yang sedang, dan sub variabel penyandang disabilitas memiliki nilai kerentanan yang rendah. Sub variabel penyandang disabilitas pada kelurahan tersebut dengan kategori kerentanan yang rendah membuat kedua kelurahan tersebut tidak begitu rentan saat terpapar bencana rob, dikarenakan jumlah penduduk penyandang disabilitas pada kedua kelurahan ini rendah.

\section{KESIMPULAN}

Berdasarkan hasil analisis nilai kerentanan sosial yang dilakukan pada tiap-tiap kelurahan di Kecamatan Semarang Utara, dengan menggunakan 6 sub variabel yang telah ditentukan dalam sintesa literatur. Kecamatan Semarang utara memiliki 3 kategori nilai kerentanan, yaitu kerentanan tinggi, sedang dan rendah, dimana dari ketiga kategori ini, kerentanan sosial tinggi yang disebabkan oleh rob menjadi nilai kerentanan yang dominan di Kecamatan Semarang Utara dikarenakan mendominasi 4 dari 9 kelurahan yang terdapat pada wilayah studi, atau dalam hal ini sebesar $45 \%$ wilayah Semarang Utara memiliki nilai kerentanan tinggi. Nilai kerentanan sosial yang tinggi di Kecamatan Semarang Utara juga dikarenakan lokasinya yang berbatasan langsung dengan tepi Laut Jawa sehingga lebih rentan terkena bencana rob. Oleh karena itu, dengan melihat kondisi spasial daerah dengan nilai kerentanan tinggi menjadi indikator untuk penataan kawasan perumahan di masa mendatang.

Oleh karena itu, rekomendasi yang disarankan antara lain:

1) Dengan diketahuinya kelurahan-kelurahan yang memiliki nilai kerentanan sosial akibat rob tinggi, rendah, maupun sedang, dapat dijadikan arahan serta pertimbangan dalam melakukan penanganan agar lebih tepat sasaran sesuai dengan kebutuhan mengingat telah diketahuinya kelurahankelurahan yang memiliki urgensi lebih tinggi untuk diperhatikan berdasarkan nilai kerentanan yang telah di analisis.

2) Untuk daerah dengan nilai kerentanan sosial tinggi yang disebabkan oleh rendahnya peran wanita, dapat dilakukan edukasi pada perempuan-perempuan di kelurahan terkait sehingga mereka memiliki pengetahuan mengenai hal-hal yang perlu dilakukan saat bencana rob dan mampu memulihkan diri pasca bencana rob.

3) Untuk daerah dengan nilai kerentanan sosial tinggi yang disebabkan oleh pekerjaan dan pendapatan, hendaknya dipahami pula bukan sabagai penyebab tunggal sehingga harus ditangani seiringan dengan sub variabel lainnya. Seperti perbaikan pada kondisi pendidikan dengan memaksimalkan program pemerintah terkait pendidikan minimal 12 tahun agar mereka memiliki kesempatan kerja yang lebih baik sehingga mendapatkan pendapatan yang cukup.

4) Untuk daerah dengan nilai kerentanan sosial tinggi yang disebabkan oleh rasio ketergantungan penduduk usia tua dan balita terhadap penduduk berusia produktif yang tinggi, dapat dilakukan dengan mengedukasi masyarakat non produktif agar mampu menyelamatkan dan memulihkan diri 
mereka saat terjadinya bencana, dan agar hal ini dapat menjadi perhatian saat dilakukannya evakuasi agar golongan ini menjadi salah satu yang di prioritasikan.

5) Untuk daerah dengan nilai kerentanan sosial yang tinggi yang diakibatkan oleh penyandang disabilitas, hendaknya diberikan jalur evakuasi khusus bagi penyandang disabilitas guna memudahkan proses evakuasi atau distribusi bantuan.

\section{PERNYATAAN RESMI}

Penulis mengucapkan terima kasih kepada Masyarakat Kecamatan Semarang Utara, Kota Semarang dan kepada Departemen Perencanaan Wilayah dan Kota, Fakultas Teknik, Universitas Diponegoro yang telah membantu penelitian ini.

\section{REFERENSI}

Adger, W. N. (2006). Vulnerability. Global Environmental Change, 16(3), 268-281.

Alwang, J., Siegel, P. B., \& Jorgensen, S. L. (2001). Vulnerability: A View From Different Disciplines. Discussion Paper Series No. 0115 Social Protection Unit, The World Bank.

Birkmann, J. (2007). Risk and Vulnerability Indicators at Different Scales: Applicability, Usefulness and Policy Implications. Environmental Hazards, 7(1), 20-31.

Buchori, I., Pramitasari, A., Sugiri, A., Maryono, M., Basuki, Y., \& Sejati, A. W. (2018). Adaptation to Coastal Flooding and Inundation: Mitigations and Migration Pattern in Semarang City, Indonesia. Ocean |\& Coastal Management, $163,445-455$.

Cutter, S. L., \& Finch, C. (2008). Temporal and Spatial Changes in Social Vulnerability to Natural Hazards. Proceedings of the National Academy of Sciences, 105(7), 2301-2306.

Cutter, S. L., Mitchell, J. T., \& Scott, M. S. (2000). Revealing the Vulnerability of People and Places: A Case Study of Georgetown County, South Carolina. Annals of the Association of American Geographers, 90(4), 713-737.

Emrich, C. T., \& Cutter, S. L. (2011). Social Vulnerability to Climate-Sensitive Hazards in the Southern United States. Weather, Climate, and Society, 3(3), 193-208.

Flanagan, B. E., Gregory, E. W., Hallisey, E. J., Heitgerd, J. L., \& Lewis, B. (2011). A Social Vulnerability Index for Disaster Management. Journal of Homeland Security and Emergency Management, 8(1). https://doi.org/10.2202/15477355.1792

Gu, H., Du, S., Liao, B., Wen, J., Wang, C., Chen, R., \& Chen, B. (2018). A hierarchical pattern of urban social vulnerability in Shanghai, China and its implications for risk management. Sustainable Cities and Society, 41(March), 170-179. https://doi.org/10.1016/j.scs.2018.05.047

Marfai, M. A., \& King, L. (2007). Monitoring Land Subsidence in Semarang, Indonesia. Environmental Geology, 53(3), 651-659.

Suhelmi, I. R. (2009). Pemanfaatan Multimedia dalam Visualisasi Model Rob Berbasis Sistem Informasi Geografi di Semarang. Jurnal Kebencanan Indonesia, 2(2), 25-31.

Tika, P. (2005). Metode Penelitian Geografi. Bumi Aksara.

UNISDR. (2004). Natural Disasters : Rich Countries Also Pay Their Toll.

Yuliastuti, N., Rahdriawan, M., \& Soetomo, S. (2016). Community Resilience in Overcoming Untidiness Due to the Flood in Kemijen Village Semarang. In International Conference on Social Science and Management. Osaka.

Yuwono, B. D. (2013). Korelasi Penurunan Muka Tanah dengan Penurunan Muka Air Tanah di Kota Semarang. Teknik, 34 No. 3(3), 188-195. 